\title{
Treatment for chronic myelogenous leukemia: the long road to imatinib
}

\author{
Tony Hunter \\ Molecular and Cell Biology Laboratory, Salk Institute for Biological Studies, La Jolla, California, USA.
}

\begin{abstract}
The scientists of today have become accustomed to the extremely rapid pace of progress in the biomedical sciences spurred on by the discovery of recombinant DNA and the advent of automated DNA sequencing and PCR, with progress usually being measured in months or years at most. What is often forgotten, however, are the many prior advances that were needed to reach our present state of knowledge. Here I illustrate this by discussing the scientific discoveries made over the course of the past century and a half that ultimately led to the recent successful development of drugs, particularly imatinib mesylate, to treat chronic myelogenous leukemia.
\end{abstract}

Chronic myelogenous leukemia (CML) is a hematological stem cell disorder characterized by excessive proliferation of cells of the myeloid lineage. The genetic hallmark of CML is the Philadelphia chromosome, which arises from a reciprocal translocation between chromosomes 9 and 22 that fuses the c- $A B L$ (cellular homolog of the Abelson murine leukemia virus oncogene product) tyrosine kinase gene on chromosome 9 and the breakpoint cluster region $(B C R)$ gene on chromosome 22. The BCR-v-Abl Abelson murine leukemia viral oncogene homolog $(B C R-A B L)$ fusion gene encodes a constitutively active BCR$\mathrm{ABL}$ tyrosine kinase that plays a causal role in CML. The disease is characterized by a chronic phase that can last for months or years and may exhibit few or no symptoms. Eventually, the chronic phase progresses to a more dangerous accelerated or acute (blast crisis) phase, during which the leukemia cells acquire additional genetic changes, proliferate more rapidly and become resistant to apoptosis, and, if untreated, ultimately cause the patient's demise (1).

The disease was first recognized in 1845 independently by John Hughes Bennett (2) and David Craigie (3), working together in Edinburgh, and Rudolf Virchow $(4,5)$ in Berlin, who showed that $\mathrm{CML}$ is a blood cell disease characterized by excessive white blood cell accumulation (Figure 1). In the first documented attempt at therapy, Heinrich Lissauer reported in 1865 that arsenous oxide (in the form of Fowler's solution - arsenic trioxide dissolved in 1\% $\mathrm{w} / \mathrm{v}$ potassium bicarbonate) was effective in the treatment of CML (6); arsenic trioxide was "rediscovered" as a CML therapy in the 1930s (7) and, interestingly, has recently once again undergone a renaissance as a treatment for acute promyelocytic leukemia (APL) (8), where it causes induction of apoptosis and partial differentiation of APL cells.

\section{The first clues to the molecular basis of CML}

Little progress was made in understanding CML until the advent of high-resolution karyotyping, which allowed Peter Nowell and David Hungerford in 1960 to identify a consistent chromosomal abnormality in the myeloid blasts, namely a small deletion at the

Nonstandard abbreviations used: ABL, v-Abl Abelson murine leukemia viral oncogene homolog; BCR, breakpoint cluster region; c-ABL, cellular homolog of v-ABL; CML, chronic myelogenous leukemia; c-Src, cellular homolog of the Rous sarcoma virus oncogene product; GIST, gastrointestinal stromal tumor; RSV, Rous sarcoma virus; $\mathrm{SH} 2$, Src homology 2; v-ABL, Abelson murine leukemia virus oncogene product; $\mathrm{v}$-Src, Rous sarcoma virus oncogene product.

Conflict of interest: The author has declared that no conflict of interest exists. Citation for this article: J. Clin. Invest. 117:2036-2043 (2007). doi:10.1172/JCI31691. end of chromosome 22, which became known as the Philadelphia chromosome (9). Ten years later, Janet Rowley, using the newly developed technique of chromosome banding, deduced that this was in fact due to a reciprocal translocation $\mathrm{t}(9 ; 22)(\mathrm{q} 34 ; \mathrm{q} 11)$, in which the tip of the long arm of chromosome 9 (q34-ter) is swapped for the tip of the long arm of chromosome 22 (q11-ter) (10). Again, there was a gap of several years before Nora Heisterkamp, Jon Groffen, John Stephenson, and Gerard Grosveld (11-13), using fragments of the recently cloned Abelson murine leukemia virus oncogene $(\mathrm{v}-a b l)$ and $\mathrm{c}-A B L$ genes, determined that CML translocations interrupt the c- $A B L$ gene on chromosome 9, fusing its $3^{\prime}$ half to the $5^{\prime}$ half of a novel gene on chromosome 22, which they termed the BCR gene. Grosveld, Groffen, and Heisterkamp and Eli Canaani's group then showed that a chimeric $B C R$ $A B L$ mRNA is generated in CML cells $(14,15)$. Subsequent studies from groups led by Owen Witte and David Baltimore identified the protein product of the $B C R-A B L$ chimeric mRNA in CML as a $210-\mathrm{kDa} B C R-A B L$ protein, larger than the $150-\mathrm{kDa}$ endogenous $c-A B L$ protein $(16,17)$. It was already known from Witte and Baltimore's previous work that $\mathrm{v}$-Abl has tyrosine kinase activity (18), and Jamie Konopka, Susan Watanabe, and Witte were quickly able to show that BCR-ABL not only has tyrosine kinase activity but also has more potent kinase activity than c-ABL, presumably as a result of the structural difference (16).

\section{The v-Abl and v-Src oncoproteins and tyrosine phosphorylation}

As must be evident, these discoveries had all depended on the prior work on Abl, which began in 1970 with Herbert Abelson and Louise Rabstein's isolation of the Abelson murine leukemia virus, which causes nonthymic lymphoma in mice (19). As is the case for all acutely transforming RNA tumor viruses (retroviruses), the genesis of Abelson virus involved the incorporation of a fragment of a cellular gene, in this case c-abl, into the viral RNA genome. These captured cellular sequences encode a key part of the viral transforming protein, $\mathrm{v}$-Abl. Characterization of the Abelson virus gene products led to the identification of a $120-\mathrm{kDa} \mathrm{v}-\mathrm{Abl}$ oncoprotein, which is a fusion of the viral Gag protein with an N-terminally truncated c-Abl protein $(20,21)$; the subsequent cloning and sequencing of the $\mathrm{v}$-abl gene provided a predicted amino acid sequence for the $\mathrm{v}$-Abl protein, which proved to have significant similarity to the sequences of other oncogenic protein kinases, such as Rous sarcoma virus oncogene product (v-Src) (22). Indeed, 


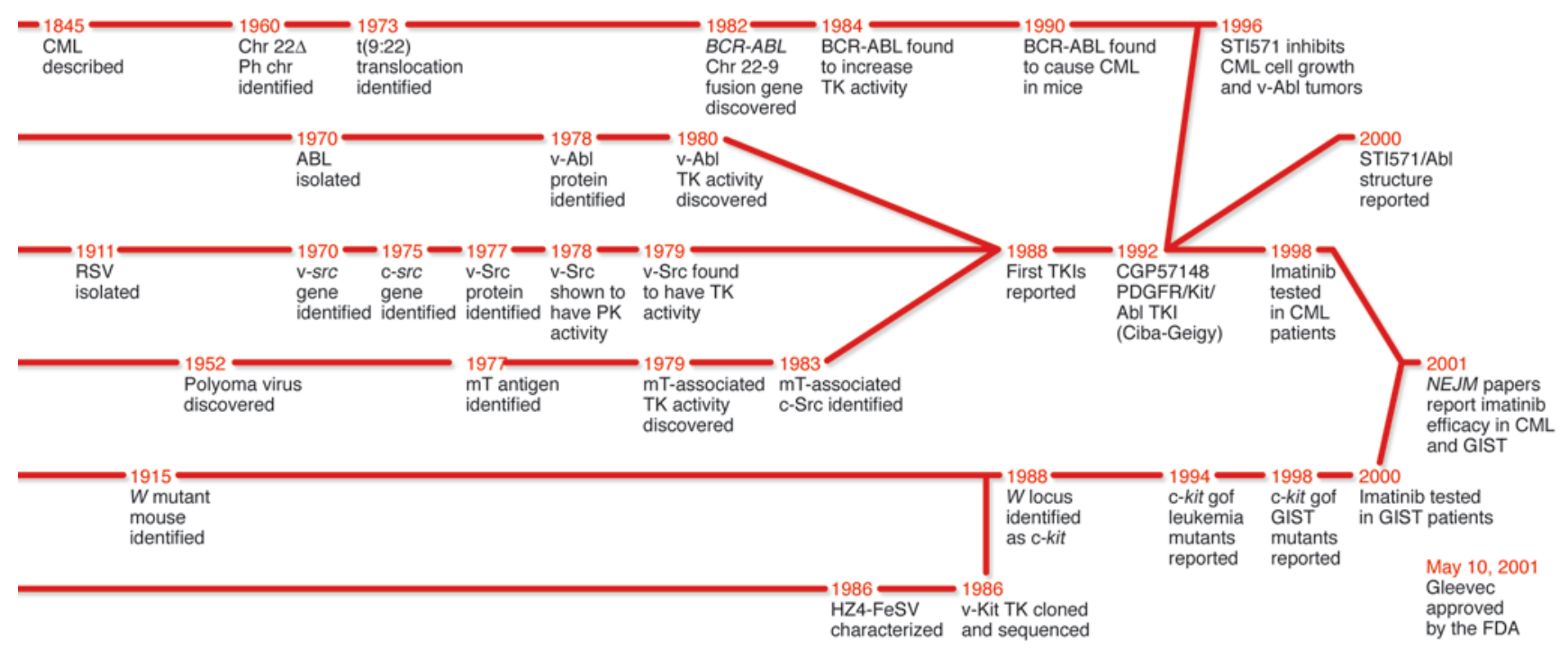

Figure 1

A timeline of the different avenues of research endeavor that came together and led to the successful development of imatinib as a treatment for CML. Most of these disparate research efforts were started through a desire to understand the mechanisms underlying cancer and to ultimately develop therapies. A significant acceleration in progress came in the 1970s with Nixon's "war on cancer," which brought a lot of new people and ideas into the cancer field. The advent of molecular cloning and DNA sequencing in the mid-1970s also played a critical role, allowing for the identification of oncogenes and their products. gof, gain-of-function; HZ4-FeSV, Hardy-Zuckerman 4 feline sarcoma virus; mT, middle T antigen; NEJM, New England Journal of Medicine; Ph chr, Philadelphia chromosome; PK, protein kinase; TK, tyrosine kinase; TKI, tyrosine kinase inhibitor.

another crucial thread of research that contributes to the story began in 1911 with Peyton Rous' isolation of a chicken sarcoma virus, which became known as Rous sarcoma virus (RSV). The study of the RSV acutely transforming retrovirus eventually led to the pivotal discovery by Dominique Stehelin, Mike Bishop, Harold Varmus, and Peter Vogt in 1976 that the RSV oncogene, v-src, was a captured cellular gene, c-src (cellular homolog of $\mathrm{v}-s r c$ ) (23). Not only was this the first identification of a viral oncogene, which established the principle that all acutely transforming retroviruses have acquired cellular sequences, but it also confirmed the existence of cellular oncogenes, first posited by Huebner and Todaro in 1969 (24). Later work showed that the c-src gene underwent a small C-terminal truncation during its acquisition by RSV, resulting in its oncogenic activity (see below). Joan Brugge and Ray Erikson identified the $\mathrm{v}-\mathrm{src}$ gene product as a $60-\mathrm{kDa}$ protein, known as $\mathrm{v}$-Src (25), and Marc Collett, Brugge, and Erikson identified c-Src, the closely related product of the c-src gene (26). Then, in another key advance, Collett and Erikson and Bishop, Varmus, and colleagues showed that $\mathrm{v}$-Src has an associated protein kinase activity that correlates with the transforming potential of $\operatorname{RSV}(27,28)$.

Initially, v-Src was reported to have threonine kinase activity (27), but subsequent studies on another type of tumor virus, the polyomavirus DNA tumor virus, showed that the protein kinase activity associated with the polyomavirus middle $\mathrm{T}$ antigen was specific for tyrosine, at the time a totally new type of protein kinase (29). This led to a reevaluation of the $\mathrm{v}$-Src kinase specificity. $\mathrm{v}$-Src also proved to function as a tyrosine kinase both in vitro and in vivo. Moreover, $\mathrm{v}$-Src activity was found to lead to a large increase in the level of phosphotyrosine in cellular proteins that is essential for malignant transformation (30). Within a year, three other distinct retroviral oncoproteins had been reported to have tyrosine kinase activity $(18,31,32)$, and the EGF receptor had also been shown to have EGF-induced tyrosine kinase activity (33), providing the first concrete link between oncogenesis and growth control and, more importantly, setting the stage for the subsequent development of tyrosine kinase inhibitors as cancer drugs.

\section{Lessons from other tumor viruses}

Polyomavirus redux. In the early days of cancer research, the SV40 and polyomavirus DNA tumor viruses, with their small circular DNA genomes, served as important cancer models. Polyomavirus was discovered by Ludwik Gross as a contaminant in a murine leukemia virus preparation in the early 1950s and was termed polyomavirus by Sarah Stewart, Bernice Eddy, and Ninette Borgese (34) because it elicited multiple types of tumors in mice. Studies of polyomavirus continued to have an important impact, even after the discovery of tyrosine phosphorylation. For instance, Sara Courtneidge and Alan Smith demonstrated that, in contrast to $\mathrm{v}$-Src, the tyrosine kinase activity associated with polyomavirus middle $T$ was not an intrinsic activity but rather the result of the activity of a tightly bound cellular tyrosine kinase, which proved to be none other than $\mathrm{c}-\mathrm{Src}$, the progenitor of $\mathrm{v}$-Src (35). Binding of middle $\mathrm{T}$ antigen to $\mathrm{c}$-Src results in its activation as a kinase, and Courtneidge showed that this was due to decreased tyrosine phosphorylation of c-Src at an inhibitory site (36). This site was mapped to Tyr527 at the very C terminus of c-Src, beyond the catalytic domain (37), in a region that is missing from $\mathrm{v}$-Src, as a consequence of the manner in which the v-src coding region was incorporated into the RSV genome. The lack of this negative regulatory site explains why v-Src has constitutively high tyrosine kinase activity. Subsequent work has shown that Tyr527 is phosphorylated by the regulatory tyrosine kinase c-Src tyrosine kinase (CSK). From crystal structures, we learned that phosphorylated Tyr527 binds intramolecularly to the Src homology 2 (SH2) domain, which 

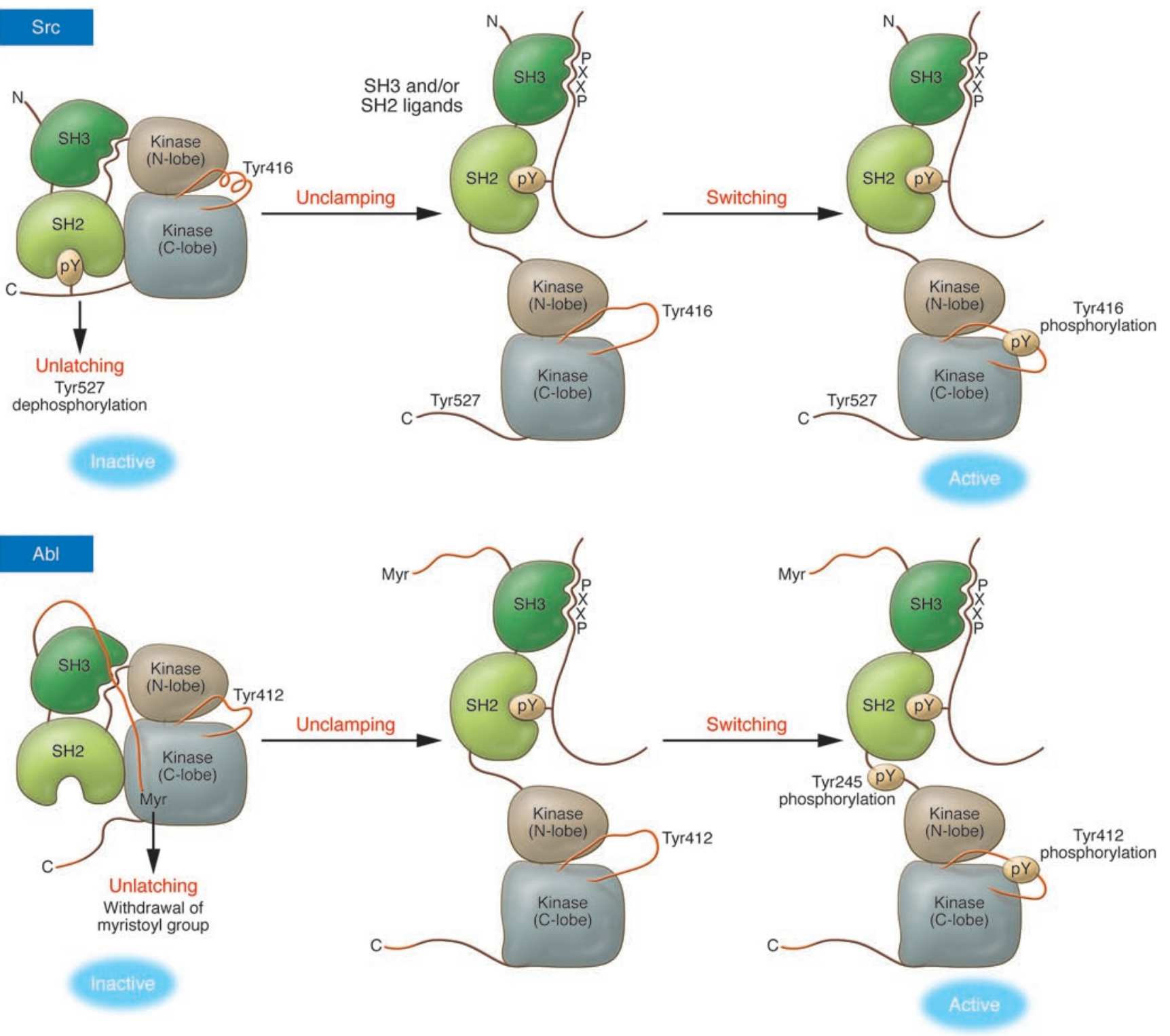

Figure 2

C-Src and c-Abl have similar negative regulatory mechanisms. Figure modified with permission from Cell (40). C, C terminus; N, N terminus; pY, phosphorylated tyrosine.

in turn allows the SH3 domain to bind through its Pro-specific ligand-binding groove to the linker between the catalytic domain and the SH2 domain, thereby locking the N-terminal lobe of the catalytic domain into an inactive configuration $(38,39)$ (Figure 2). It turns out that there are striking parallels between the way in which the $\mathrm{SH} 2$ and $\mathrm{SH} 3$ domains act to negatively regulate c-Src catalytic domain activity and the way in which the c-Abl SH2 and SH3 domains inhibit c-Abl kinase activity (40) (Figure 2 and see below), and taken together these structures explain why the mutations in $\mathrm{v}-\mathrm{Abl}$ and $\mathrm{BCR}-\mathrm{ABL}$ convert them into constitutively active tyrosine kinases.

The W gene, Kit, and the Hardy-Zuckerman 4 feline sarcoma virus. Yet another line of research pertinent to the imatinib story began at The Jackson Laboratory in 1915 with C.C. Little's identification of a mouse dominant white-spotting mutant (W) (41). Further analysis in the 1920s by Sonya de Aberle showed that the lethal phenotype of WW homozygous mutant mice is due to anemia (42). Over the years a series of $W$ mutations were collected, but the identity of the causative gene remained unknown until 1986, when characterization of a recently isolated feline sarcoma virus, HardyZuckerman 4 feline sarcoma virus, led to the discovery of a new viral oncogene, aptly named v-kit, by Peter Besmer, who went on to clone and sequence the gene (43). Based on the deduced amino acid sequence, the v-Kit protein, which like v-Abl is a Gag fusion protein, was predicted to be a tyrosine kinase, and this proved to be the case (44). The v-Kit domain structure implied that it was derived from a receptor tyrosine kinase, and this was born out by the cloning of the c-KIT gene, which encodes a receptor tyrosine kinase closely related to the PDGF receptor (45-47), whose ligand is stem cell factor. The v-Kit protein is anchored to the plasma membrane by the 


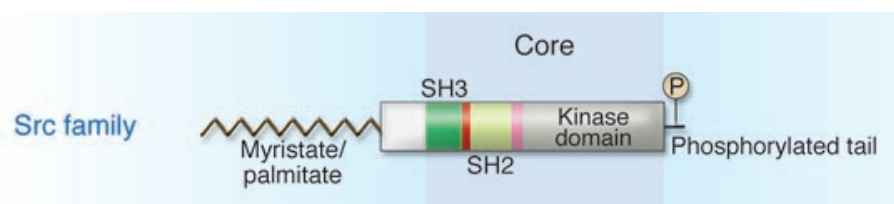

Src, Yes, Fyn, Lyn, Lck, Blk Hck, Fgr, Yrk

\section{Figure 3}

Structures of Src and Abl family tyrosine kinases and BCR-ABL. Figure modified with permission from Nature Reviews Molecular Cell Biology (113).
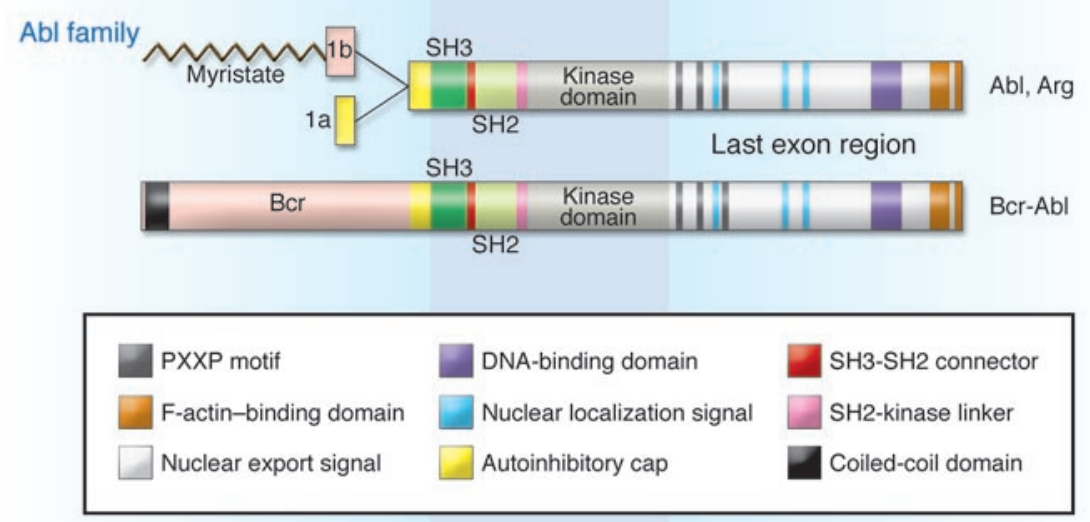

portion of the protein, which has a coiledcoil motif, itself contributes to the transforming function by serving as an oligomerization domain (59-61). The BCR-ABL $\mathrm{SH} 2$ domain is critical for transformation of fibroblasts (62), as was shown earlier for $\mathrm{v}$-Abl transformation (63), but not hematopoietic cells (64), although its presence influences disease latency and phenotype (65). Only more recently has it been appreciated that the absence of the c-ABL N-terminal "cap" region in the BCR-ABL fusion protein is also important because the cap normally folds back and locks the SH2$\mathrm{SH} 3$ unit onto the backside of the catalytic

myristoyl group at the $\mathrm{N}$ terminus of the Gag sequence, and this combined with the lack of a critical negative regulatory cytoplasmic juxtamembrane region as well as both the extracellular and transmembrane domains renders $\mathrm{v}$-Kit constitutively active and able to activate receptor tyrosine kinase signaling pathways.

The chromosomal mapping of c-kit to mouse chromosome 5 (45) immediately suggested to two groups that it might be the long-sought $W$ locus gene, and their analysis showed that the c-Kit protein is subject to a series of loss-of-function mutations in the different $W$ mutant alleles $(48,49)$, such that the mutant proteins lack kinase activity and thereby function in a dominant-negative fashion to reduce wild-type c-Kit activity in heterozygotes, leading to the observed hematopoietic, gametogenesis, and melanogenesis defects. However, the relevance, if any, of the c-KIT gene to human disease remained unclear until 1994, when Yukihiko Kitamura's group reported that rare mast cell leukemias have a gain-of-function c-KIT mutation (50). Even more excitingly, the same group later showed that many gastrointestinal stromal tumors (GISTs), which arise from the interstitial cells of Cajal, have small deletions and duplications in the cytoplasmic juxtamembrane domain of c-KIT, which are also gain-of-function mutations $(51,52)$. The kinase activity of the activated c-KIT deletion mutant proteins is inhibited by imatinib.

\section{BCR-ABL transformation mechanisms}

Work on BCR-ABL continued apace, and another important step was the demonstration in 1990 by three groups that mouse bone marrow cells engineered to express BCR-ABL gave rise to a myeloid leukemia very similar to CML upon inoculation into irradiated recipient mice (53-55), and by a fourth group that a $B C R-A B L$ transgene also induced a myeloid leukemia in mice (56). Based on the predicted amino acid sequence of the $210-\mathrm{kDa} B C R-A B L$ protein $(57,58)$, one can deduce its domain structure (Figure 3 ): the $\mathrm{N}$-terminal BCR sequences are joined upstream of the c-ABL SH3 and $\mathrm{SH} 2$ domains, followed by the catalytic domain and the C-terminal half of c-ABL, which has several functional motifs including nuclear export and import sequences and an actin-binding motif. Analysis of mutated forms of BCR-ABL has shown that the BCR domain, allowing the $\mathrm{N}$-terminal myristoyl group to bind into a pocket on the C-terminal lobe of the catalytic domain, holding it in an inactive configuration (66-68) (Figure 2). Interestingly, although v-Abl itself lacks the SH3 domain and deletion of the $\mathrm{SH} 3$ domain renders a myristoylated form of c-ABL transforming, presumably because this relieves the inhibitory influences of the $\mathrm{SH} 3$ domain on the kinase domain, BCR-ABL retains the SH3 domain. In this case, its negative regulatory effect is overridden by BCR-ABL autophosphorylation at Tyr1127 in the SH2 catalytic domain linker, which disrupts its binding to the SH3 domain (69). Although the BCR-ABL SH3 domain is not required for myeloid transformation (70), there is some evidence that it has a role in BCR-ABL-induced leukemogenesis (71).

Additional analysis of BCR-ABL showed that the conserved C-terminal F-actin-binding domain also contributes to transformation (72). Unlike c-Abl, which shuttles between the nucleus and cytoplasm, BCR-ABL is largely cytoplasmic and localizes in part to F-actin-containing structures through its C-terminal F-actin-binding domain. The cytoplasmic localization of BCR-ABL coupled with its unregulated tyrosine kinase activity allows it to usurp signaling pathways normally activated by growth factor receptor tyrosine kinases, such as the EGF and PDGF receptors, or cytokine receptors that utilize nonreceptor tyrosine kinases, such as Src and JAK family kinases, for signaling. A true mechanistic understanding of BCR-ABL-induced leukemogenesis requires a knowledge of the key signaling pathways that it activates, and this in turn requires identification of proteins that are phosphorylated by BCR-ABL.

Efforts to identify specific targets of the BCR-ABL kinase began early on, using both anti-phosphotyrosine blotting and twodimensional gel analysis (73-75). Subsequently, several BCR-ABL targets have been identified whose tyrosine phosphorylation is increased in CML cells, including the E3 ubiquitin ligase the cellular homolog of the Casitas B-lineage lymphoma v-cbl oncogene (c-CBL), the $\mathrm{SH} 2 / \mathrm{SH} 3$ adaptor proteins CRKL, CRK, GRB2 (growth factor receptor-bound protein 2), and VAV as well as paxillin, STAT5, and DOK1 (docking protein 1). Exactly which BCRABL targets are key to the growth of CML leukemic cells is still unclear, but monitoring the tyrosine phosphorylation status of 
these proteins in leukemic cells isolated from patients is a convenient way to determine the effectiveness of imatinib therapy. In addition, a number of $\mathrm{SH} 3$ domain-signaling proteins interact with BCR-ABL through four ProXXPro motifs downstream of the catalytic domain, such as the PI3K p85 regulatory subunit and NCK. BCR-ABL autophosphorylates at several residues, including Tyr1294 (which corresponds to Tyr412 in c-ABL) in the activation loop and Tyr1127 (which corresponds to Tyr245 in c-ABL) in the SH2 catalytic domain linker; both of these phosphorylations increase catalytic activity (69). BCR-ABL also autophosphorylates at Tyr177 in the BCR domain, which has the interesting consequence of promoting SH2-dependent binding of GRB2 and activating RAS/ERK signaling (76). This fortuitous gain-of-function phenotype is important, since a Tyr177Phe mutation abrogates BCR-ABL transforming activity (76).

\section{The first tyrosine kinase inhibitors}

The realization in the early 1980s that activated tyrosine kinases such as v-Src, v-Abl, and BCR-ABL could have a causal role in cancer, combined with the discovery of additional viral and cellular oncogenes that encoded tyrosine kinases, engendered a serious interest in the development of small molecule inhibitors of oncogenic tyrosine kinases with the hope that they might ultimately be useful in cancer therapy. The question was whether it would be possible to develop specific tyrosine kinase inhibitors. All protein kinases use ATP as the phosphate donor, transferring the $\gamma$-phosphate of ATP onto the acceptor amino acid in the target protein. The largest class of eukaryotic protein kinases, which includes almost all of the serine/threonine and tyrosine kinases, has a highly conserved ATP-binding site, and at the time the only known protein kinase inhibitors were competitive with ATP. As a consequence there were many naysayers who argued that it would be impossible to develop specific protein kinase inhibitors because of the problems of generating inhibitors that would bind selectively to the conserved ATP-binding site in different protein kinases and because it would be difficult for such inhibitors to compete effectively with the millimolar intracellular ATP levels. Nonetheless, cell-permeant protein kinase inhibitors began to be reported, and efforts to develop tyrosine kinase inhibitors began, first in academia and then in industry.

In academia, a number of natural products were shown to act as tyrosine kinase inhibitors (77-81), and the first attempts at rational design of tyrosine kinase inhibitors were undertaken by Alex Levitzki (82), emboldened by the pioneering work of Hiroyoshi Hidaka, who had shown that it was possible to develop specific synthetic inhibitors of serine kinases (83). Levitzki called these inhibitors tyrphostins (tyrosine phosphorylation inhibitors), and they were initially modeled after erbstatin, a natural tyrosine kinase inhibitor that contains a tyrosine ring mimic (82). Among the first series of tyrphostins were selective inhibitors of BCRABL (84), including AG568, AG957 (adaphostin), and AG1112, which induced the K562 CML cell line to terminally differentiate into nondividing erythroid cells (85). Interestingly, two of the first selective tyrosine kinase inhibitors developed by the Levitzki group, the EGFR inhibitor AG1478 (86) and the PDGFR inhibitor AG1296 (87) are still widely used as research tools.

\section{BCR-ABL inhibitors become drugs}

At the time when it became clear that BCR-ABL would be a valid cancer drug target, there were relatively few kinase inhibitor pro- grams in the pharmaceutical industry. CIBA-Geigy (now Novartis) established a serine kinase inhibitor program in 1984 under the direction of Alex Matter and subsequently initiated a tyrosine kinase inhibitor effort in 1986 led by Nick Lydon (88). An early target was the PDGF receptor, and CGP53716, a 2-phenylaminopyrimidine derivative synthesized as a member of a series by Juerg Zimmermann (89), was shown by Elisabeth Buchdunger to selectively inhibit PDGF receptor signaling and the growth of $\mathrm{v}$-sis-transformed BALB/c 3 T3 cells, which are dependent on $v$-Sis activation of endogenous PDGF receptors (90). The same series of 2-phenylaminopyrimidines yielded CGP57148B, which inhibits the PDGF receptor and $\mathrm{v}-\mathrm{Abl}$ in vitro and in vivo equally potently (91) and also BCR-ABL (92). CGP57148B became known as STI571 (signal transduction inhibitor 571) and is now called imatinib (the generic name). When formulated as the mesylate salt, imatinib is marketed by Novartis as Gleevec (in the USA) or Glivec (in Europe).

Brian Druker, a physician scientist and fellow contributor to this Review Series, had been working on CML since the early 1990s, and once he set up his own group at Oregon Health \& Science University in Portland in 1993 and started treating CML patients, he became determined to find a better treatment for this disease. The logical approach was to develop a small molecule inhibitor of the BCR-ABL tyrosine kinase activity, since this would be expected to block the growth of the transformed cells. To try to find a suitable inhibitory compound, he collaborated with the members of the tyrosine kinase inhibitor program at CIBA-Geigy. Working closely with Lydon, Buchdunger, and Zimmermann, Druker identified CGP57148B as a potent and relatively selective $\mathrm{v}$-Abl inhibitor. Together with Buchdunger, Druker showed that CGP57148B was able to inhibit the growth of CML cells and BCR-ABL-transformed cells both in culture and when grown as tumors in mice $(92,93)$. There was little evidence of toxicity in mice, and, emboldened by these results, in June 1998 Druker and Charles Sawyers initiated a phase I/II clinical trial in chronic phase CML patients resistant to prior interferon therapy (94). This trial, and subsequent largescale follow-up phase II clinical trials, showed that imatinib was very effective in treating chronic phase CML and had palliative, but usually not long-lasting, effects in the acute blast crisis phase $(95,96)$ that were commonly due to the development of resistance mutations in BCR-ABL itself. These successes led to an accelerated approval process by the FDA, and imatinib was approved for the treatment of CML on May 10, 2001.

Fortuitously, in one sense, imatinib not only inhibits BCR$\mathrm{ABL}$ but is closely related to, and almost equally potent against PDGFR $\alpha$, as c-KIT receptor tyrosine kinases (97). Both imatinib and c-KIT receptor tyrosine kinases are implicated through activating mutations in GIST $(51,52,98)$, and this led George Demetri to test imatinib in the treatment of GIST patients, whose tumors express activated c-KIT. He found that imatinib was quite effective in such patients, in some cases causing rapid tumor regression (99). This led to a full-fledged clinical trial, and imatinib was approved for the treatment of GIST in February 2002. Imatinib has also been found to have uses in the treatment of other proliferative premalignant hematopoietic diseases, including hypereosinophilia syndrome and chronic eosinophilia leukemia, which also express an activated form of PDGFR $\alpha$.

\section{The remaining challenges}

What does the future of molecularly based CML therapy hold? Although imatinib is a remarkably effective treatment for chronic 
Table 1

Cancer drugs that act against tyrosine kinases

$\begin{array}{lll}\text { Drug } & \text { Cancer } & \text { Target } \\ \text { Small-molecule drugs } & & \\ \text { Imatinib (Gleevec) } & \text { Leukemia (CML) } & \text { BCR-ABL tyrosine kinase } \\ \text { Gefitinib (Iressa) } & \text { Lung cancer } & \text { EGFR tyrosine kinase } \\ \text { Erlotinib (Tarceva) } & \text { Lung cancer } & \text { EGFR tyrosine kinase } \\ \text { Sunitinib (Sutent) } & \text { GIST/renal carcinoma } & \text { KIT receptor tyrosine kinase } \\ \text { Dasatinib (Sprycel) } & \text { Leukemia (CML) } & \text { BCR-ABL tyrosine kinase } \\ \text { Lapatinib (Tykerb) } & \text { Breast cancer } & \text { ERBB2 receptor tyrosine kinase } \\ \text { Many in clinical trials } & \text { Several types/AML } & \text { Angiogenesis/FLT3 receptor tyrosing } \\ \text { kinases } & & \\ \text { Monoclonal antibody drugs } & & \\ \text { Trastuzumab (Herceptin) } & \text { Breast cancer } & \text { ERBB2 receptor tyrosine kinase } \\ \text { Cetuximab (Erbitux) } & \text { Breast/renal cancer } & \text { EGFR tyrosine kinase } \\ \text { Cevacizumab (Avastin) } & \text { Colon cancer } & \text { VEGF }\end{array}$

More than 70 protein kinase inhibitors are in cancer clinical trials, including several directed against serine/ threonine kinases implicated in cancer. The RAF inhibitor sorafenib (Nexavar) has recently been approved for treatment of renal cell carcinoma. Rapamycin, an mTOR kinase inhibitor, and rapamycin analogues are also in clinical trials for several cancers.

a combination of imatinib and dasatinib seems to be more effective than either alone as primary treatment. Perhaps Src family kinases play an important role in acute phase CML; if so, the ability of dasatinib to inhibit both Src and Abl would then explain why this combination is more effective. Ideally one would like to design combination therapy on a more rational basis, but for this we need a better understanding of the molecular basis of latestage disease. Like other cancers, CML is thought to be a stem celldriven disease, and the true target cell that initiates CML may be a granulocyte-macrophage-like progenitor cell (109). The ability to isolate leukemic stem cells from CML patients has begun to

phase CML, imatinib resistance does occur, particularly in blast crisis patients and usually as a result of mutations in BCR-ABL, in particular the prevalent Thr315Ile (T315I) mutation $(100,101)$. This has led to efforts to develop second generation BCR-ABL inhibitors that can block the activity of these imatinib-resistant mutant forms of BCR-ABL. In clinical trials, dasatanib, a c-Src and $\mathrm{c}-\mathrm{Abl}$ inhibitor, proved effective in CML therapy and works against most of the imatinib-resistant BCR-ABL mutations, but not against Thr315Ile (102). In June 2006, dasatanib (also known as Sprycel) was approved by the FDA for the treatment of patients with CML who showed resistance or intolerance to prior therapy. Nilotinib (also known as Tasigna), a derivative of imatinib that is also active against most of the imatinib-resistant mutations, but not against Thr315Ile BCR-ABL, has also shown promising results in clinical trials for CML and is expected to be approved soon.

The emergence of resistance to kinase inhibitors used in cancer therapy is a general phenomenon, and this has led to the development of methods to try and predetermine which mutations are likely to cause resistance (e.g., random PCR-based mutagenesis of BCR-ABL and expression in myeloid cell lines, followed by selection of imatinib-resistant cells in culture; ref. 103). An understanding of the basis of imatinib resistance has come from the elegant structural analysis of imatinib bound to the c-ABL catalytic domain (104), which helps explain how mutations distant from the residues that contact imatinib can induce resistance. The structures of these complexes also reveal how inhibitor specificity is achieved, and they have been important in the development of the second-generation BCR-ABL inhibitor nilotinib, in which the imatinib scaffold has been modified based on structural insights $(105,106)$. Methods have also been developed to identify existing kinase inhibitors that have already been evaluated in clinical trials and that might target the imatinib-resistant BCR-ABL mutants; the aurora kinase inhibitor, VX680, is a compound of this sort $(107,108)$ and is being tested clinically for the treatment of CML.

Because BCR-ABL inhibitor therapy generally only provides temporary remission in blast crisis CML patients, trials are underway to treat relapsed CML patients using a BCR-ABL kinase inhibitor in combination with other therapeutic modalities. Interestingly, lead to a mechanistic understanding of the self-renewal and leukemic properties of these cells, which might be due to activation of the $\beta$-catenin pathway (109). However, the key substrates for BCRABL phosphorylation that are important for stem cell renewal and the enhanced proliferation of their derivatives are still largely unknown. Many proteins phosphorylated by BCR-ABL have been identified, with recent phosphoproteomic analyses revealing that there are literally hundreds of tyrosine phosphorylated proteins in CML cells dependent on BCR-ABL activity $(110,111)$, and it will be a challenge to decipher how many of these tyrosine phosphorylation events, and in which combinations, are critical for CML. A knowledge of which signaling pathways are crucial might be useful in devising combinatorial therapies with different signal transduction inhibitors. In this regard, there is some evidence that targeting a second kinase, such as c-KIT, in addition to BCR-ABL (112), might be necessary for effective treatment of CML. Imatinib happens to fulfill this requirement, and this might explain the effectiveness of this drug in the treatment of CML.

Finally, imatinib was developed with short-term therapy in mind and was not tested for prolonged use. Yet its very success in treating the chronic phase of CML has led to its continued administration over years rather than weeks or months. In fact, the first patients have been on imatinib for 6 years, with surprisingly few adverse consequences. Nevertheless, as new CML drugs are developed and success at obtaining lasting remission is achieved, it is important to consider the long-term effects of administering these compounds, particularly if used in combination with other drugs.

\section{Coda}

It should be apparent from the above how many different avenues of research carried out over the course of a century and a half converged during the 1970s and 1980s to foster the development of tyrosine kinase inhibitors and ultimately lead to the approval of imatinib as a treatment for CML. Compared with the rapid pace of modern biomedical science, this might seem to have been a slow process. Nevertheless, as the first molecularly targeted small molecule drug approved for cancer therapy, imatinib's success has encouraged the pharmaceutical industry to pursue the develop- 
ment of kinase inhibitors for the treatment of cancer and other human diseases. Indeed, most major pharmaceutical companies now have kinase inhibitor programs, and by the beginning of 2007 seven protein kinase inhibitors had been approved for the treatment of cancer (Table 1). More are sure to follow.

\section{Acknowledgments}

I am grateful that the 2006 symposium to celebrate Peter Nowell and the discovery of the Philadelphia chromosome has afforded me the opportunity to take this trip down memory lane. I only hope that my recollections of the events since I joined the field in 1971 are accurate, and that I have not inadvertently omitted credit where credit is due.

Address correspondence to: Tony Hunter, Salk Institute, 10010 North Torrey Pines Road, La Jolla, California 92037-1099, USA. Phone: (858) 453-4100; Fax: (858) 457-4765; E-mail: hunter@ salk.edu.
1. Clarkson, B., Strife, A., Wisniewski, D., Lambek, C.L., and Liu, C. 2003. Chronic myelogenous leukemia as a paradigm of early cancer and possible curative strategies. Lenkemia. 17:1211-1262.

2. Bennett, J.H. 1845. Case of hypertrophy of the spleen and liver in which death took place from suppuration of the blood. Edinburgh Medical and Surgical Journal. 64:413-423.

3. Craigie, D. 1845. Case of disease of the spleen in which death took place in consequence of the presence of purulent matter in the blood. Edinburgh Medical and Surgical Journal. 64:400-413.

4. Virchow, R. 1845. Weisses Blut. Froiep's Notizen. 36:151.

5. Virchow, R. 1846. Weisses Blut und Milztumoren I. Medicinische Zeitung. 15:157-159, 163-166.

6. Lissauer, H. 1865. Zwei Faelle von Leucaemie. Berl. Klin. Wochenschr. 2:403-405.

7. Forkner, C.E., and Scott, T.F.M. 1931. Arsenic as a therapeutic agent in chronic myelogenous leukemia. JAMA. 97:3-5.

8. Zhang, T.D., et al. 2001. Arsenic trioxide, a therapeutic agent for APL. Oncogene. 20:7146-7153.

9. Nowell, P.C., and Hungerford, D.A. 1960. Chromosome studies on normal and leukemic human leukocytes. J. Natl. Cancer Inst. 25:85-109.

10. Rowley, J.D. 1973. A new consistent chromosomal abnormality in chronic myelogenous leukaemia identified by quinacrine fluorescence and Giemsa staining. Nature. 243:290-293.

11. de Klein, A., et al. 1982. A cellular oncogene is translocated to the Philadelphia chromosome in chronic myelocytic leukaemia. Nature. 300:765-767.

12. Heisterkamp, N., et al. 1983. Localization of the c-ab1 oncogene adjacent to a translocation break point in chronic myelocytic leukaemia. Nature. 306:239-242.

13. Groffen, J., et al. 1984. Philadelphia chromosomal breakpoints are clustered within a limited region, bcr, on chromosome 22. Cell. 36:93-99.

14. Shtivelman, E., Lifshitz, B., Gale, R.P., and Canaani, E. 1985. Fused transcript of abl and bcr genes in chronic myelogenous leukaemia. Nature. 315:550-554.

15. Stam, K., et al. 1985. Evidence of a new chimeric $\mathrm{bcr} / \mathrm{c}-\mathrm{abl}$ mRNA in patients with chronic myelocytic leukemia and the Philadelphia chromosome. N. Engl. J. Med. 313:1429-1433.

16. Konopka, J.B., Watanabe, S.M., and Witte, O.N. 1984. An alteration of the human c-abl protein in K562 leukemia cells unmasks associated tyrosine kinase activity. Cell. 37:1035-1042.

17. Ben-Neriah, Y., Daley, G.Q., Mes-Masson, A.M., Witte, O.N., and Baltimore, D. 1986. The chronic myelogenous leukemia-specific P210 protein is the product of the bcr/abl hybrid gene. Science. 233:212-214.

18. Witte, O.N., Dasgupta, A., and Baltimore, D. 1980. Abelson murine leukaemia virus protein is phosphorylated in vitro to form phosphotyrosine. Nature. 283:826-831.

19. Abelson, H.T., and Rabstein, L.S. 1970. Lymphosarcoma: virus-induced thymic-independent disease in mice. Cancer Res. 30:2213-2222.

20. Reynolds, F.H.J., Sacks, T.L., Deobagkar, D.N., and Stephenson, J.R. 1978. Cells nonproductively transformed by Abelson murine leukemia virus express a high molecular weight polyprotein containing structural and nonstructural components. Proc. Natl. Acad. Sci. U. S. A. 75:3974-3978.

21. Witte, O.N., Rosenberg, N., Paskind, M., Shields, A., and Baltimore, D. 1978. Identification of an Abelson murine leukemia virus-encoded protein present in transformed fibroblast and lymphoid cells. Proc. Natl. Acad. Sci. U. S. A. 75:2488-2492.

22. Reddy, E.P., Smith, M.J., and Srinivasan, A. 1983. Nucleotide sequence of Abelson murine leukemia virus genome: structural similarity of its transforming gene product to other onc gene products with tyrosine-specific kinase activity. Proc. Natl. Acad. Sci. U. S. A. 80:3623-3627.

23. Stehelin, D., Varmus, H.E., Bishop, J.M., and Vogt, P.K. 1976. DNA related to the transforming gene(s) of avian sarcoma viruses is present in normal avian DNA. Nature. 260:170-173.

24. Huebner, R.J., and Todaro, G.J. 1969. Oncogenes of RNA tumor viruses as determinants of cancer. Proc. Natl. Acad. Sci. U. S. A. 64:1087-1094.

25. Brugge, J.S., and Erikson, R.L. 1977. Identification of a transformation-specific antigen induced by an avian sarcoma virus. Nature. 269:346-348.

26. Collett, M.S., Brugge, J.S., and Erikson, R.L. 1978. Characterization of a normal avian cell protein related to the avian sarcoma virus transforming gene product. Cell. 15:1363-1369.

27. Collett, M.S., and Erikson, R.L. 1978. Protein kinase activity associated with the avian sarcoma virus src gene product. Proc. Natl. Acad. Sci. U. S. A. 75:2021-2024.

28. Levinson, A.D., Oppermann, H., Levintow, L., Varmus, H.E., and Bishop, J.M. 1978. Evidence that the transforming gene of avian sarcoma virus encodes a protein kinase associated with a phosphoprotein. Cell. 15:561-572.

29. Eckhart, W., Hutchinson, M.A., and Hunter, T. 1979. An activity phosphorylating tyrosine in polyoma $\mathrm{T}$ antigen immunoprecipitates. Cell. 18:925-933.

30. Hunter, T., and Sefton, B.M. 1980. Transforming gene product of Rous sarcoma virus phosphorylates tyrosine. Proc. Natl. Acad. Sci. U. S. A. 77:1311-1315.

31. Barbacid, M., Beemon, K., and Devare, S.G. 1980. Origin and functional properties of the major gene product of the Snyder-Theilen strain of feline sarcoma virus. Proc. Natl. Acad. Sci. U. S. A. 77:5158-5162.

32. Pawson, T., et al. 1980. A strain of Fujinami sarcoma virus which is temperature-sensitive in protein phosphorylation and cellular transformation. Cell. 22:767-775.

33. Ushiro, H., and Cohen, S. 1980. Identification of phosphotyrosine as a product of epidermal growth factor-activated protein kinase in A-431 cell membranes. J. Biol. Chem. 255:8363-8365.

34. Stewart, S.E., Eddy, B.E., and Borgese, N. 1958. Neoplasms in mice inoculated with a tumor agent carried in tissue culture. J. Natl. Cancer Inst. 20:1223-1243.

35. Courtneidge, S.A., and Smith, A.E. 1983. Polyoma virus transforming protein associates with the product of the c-src cellular gene. Nature. 303:435-439.

36. Courtneidge, S.A. 1985. Activation of the pp60c-src kinase by middle $\mathrm{T}$ antigen binding or by dephosphorylation. EMBO J. 4:1471-1477.

37. Cooper, J.A., Gould, K.L., Cartwright, C.A., and Hunter, T. 1986. Tyr527 is phosphorylated in pp60c-src: implications for regulation. Science. 231:1431-1434.

38. Sicheri, F., Moarefi, I., and Kuriyan, J. 1997. Crystal structure of the Src family tyrosine kinase Hck. Nature. 385:602-609.

39. Xu, W., Harrison, S.C., and Eck, M.J. 1997. Threedimensional structure of the tyrosine kinase c-Src. Nature. 385:595-602.

40. Harrison, S.C. 2003. Variation on an Src-like theme. Cell. 112:737-740.

41. Little, C.C. 1915. The inheritance of black-eyed white spotting in mice. Am. Nat. 49:727-740.

42. de Aberle, S.B. 1925. Hereditary anemia in mice and its correlation with dominant spotting. Am. Nat. 59:327-355.

43. Besmer, P., et al. 1986. A new acute transforming feline retrovirus and relationship of its oncogene $\mathrm{v}$-kit with the protein kinase gene family. Nature. 320:415-421.

44. Majumder, S., Ray, P., and Besmer, P. 1990. Tyrosine protein kinase activity of the HZ4-feline sarcoma virus P80gag-kit-transforming protein. Oncogene Res. 5:329-335.

45. Yarden, Y., et al. 1987. Human proto-oncogene c-kit: a new cell surface receptor tyrosine kinase for an unidentified ligand. EMBO J. 6:3341-3351.

46. Majumder, S., Brown, K., Qiu, F.H., and Besmer, P. 1988. c-kit protein, a transmembrane kinase: identification in tissues and characterization. Mol. Cell. Biol. 8:4896-4903.

47. Qiu, F.H., et al. 1988. Primary structure of c-kit: relationship with the CSF-1/PDGF receptor kinase family - oncogenic activation of v-kit involves deletion of extracellular domain and $\mathrm{C}$ terminus. EMBO J. 7:1003-1011.

48. Chabot, B., Stephenson, D.A., Chapman, V.M., Besmer, P., and Bernstein, A. 1988. The protooncogene c-kit encoding a transmembrane tyrosine kinase receptor maps to the mouse W locus. Nature. 335:88-89.

49. Geissler, E.N., Ryan, M.A., and Housman, D.E. 1988. The dominant-white spotting (W) locus of the mouse encodes the c-kit proto-oncogene. Cell. 55:185-192.

50. Tsujimura, T., et al. 1994. Ligand-independent activation of c-kit receptor tyrosine kinase in a murine mastocytoma cell line P-815 generated by a point mutation. Blood. 83:2619-2626.

51. Hirota, S., et al. 1998. Gain-of-function mutations of c-kit in human gastrointestinal stromal tumors. Science. 279:577-580.

52. Nishida, T., et al. 1998. Familial gastrointestinal stromal tumours with germline mutation of the KIT gene. Nat. Genet. 19:323-324.

53. Daley, G.Q., Van Etten, R.A., and Baltimore, D. 1990. Induction of chronic myelogenous leukemia in mice by the P210bcr/abl gene of the Philadelphia chromosome. Science. 247:824-823.

54. Elefanty, A.G., Hariharan, I.K., and Cory, S. 1990. Bcr-Abl, the hallmark of chronic myeloid leukaemia in man, induces multiple haemopoietic neo- 
plasms in mice. EMBO J. 9:1069-1078.

55. Kelliher, M.A., McLaughlin, J., Witte, O.N., and Rosenberg, N. 1990. Induction of a chronic myelogenous leukemia-like syndrome in mice with v-abl and BCR/ABL. Proc. Natl. Acad. Sci. U. S. A. 87:6649-6653.

56. Heisterkamp, N., et al. 1990. Acute leukaemia in bcr/abl transgenic mice. Nature. 344:251-253.

57. Shtivelman, E., et al. 1987. bcr-abl RNA in patients with chronic myelogenous leukemia. Blood. 69:971-973

58. Shtivelman, E., Lifshitz, B., Gale, R.P., Roe, B.A., and Canaani, E. 1986. Alternative splicing of RNAs transcribed from the human abl gene and from the bcr-abl fused gene. Cell. 47:277-284.

59. McWhirter, J.R., and Wang, J.Y. 1991. Activation of tyrosine kinase and microfilament-binding functions of $\mathrm{c}$-abl by bcr sequences in $\mathrm{bcr} / \mathrm{abl}$ fusion proteins. Mol. Cell. Biol. 11:1553-1565.

60. Muller, A.J., et al. 1991. BCR first exon sequences specifically activate the $\mathrm{BCR} / \mathrm{ABL}$ tyrosine kinase oncogene of Philadelphia chromosome-positive human leukemias. Mol. Cell. Biol. 11:1785-1792.

61. McWhirter, J.R., Galasso, D.L., and Wang, J.Y.J. 1993. A coiled-coil oligomerization domain of $\mathrm{Bcr}$ is essential for the transforming function of $\mathrm{Bcr}$ Abl oncoproteins. Mol. Cell. Biol. 13:7587-7595.

62. Afar, D.E., Goga, A., McLaughlin, J., Witte, O.N., and Sawyers, C.L. 1994. Differential complementation of Bcr-Abl point mutants with c-Myc. Science. 264:424-426.

63. Mayer, B.J., Jackson, P.K., Van Etten, R.A., and Baltimore, D. 1992. Point mutations in the abl SH2 domain coordinately impair phosphotyrosine binding in vitro and transforming activity in vivo. Mol. Cell. Biol. 12:609-618.

64. Ilaria, R.L., Jr., and Van Etten, R.A. 1995. The SH2 domain of P210BCR/ABL is not required for the transformation of hematopoietic factor-dependent cells. Blood. 86:3897-3904.

65. Zhang, X., Wong, R., Hao, S.X., Pear, W.S., and Ren, R. 2001. The SH2 domain of bcr-Abl is not required to induce a murine myeloproliferative disease; however, $\mathrm{SH} 2$ signaling influences disease latency and phenotype. Blood. 97:277-287.

66. Hantschel, O., et al. 2003. A myristoyl/phosphotyrosine switch regulates c-Abl. Cell. 112:845-857.

67. Nagar, B., et al. 2003. Structural basis for the autoinhibition of c-Abl tyrosine kinase. Cell. 112:859-871.

68. Nagar, B., et al. 2006. Organization of the SH3-SH2 unit in active and inactive forms of the c-Abl tyrosine kinase. Mol. Cell. 21:787-798.

69. Smith, K.M., Yacobi, R., and Van Etten, R.A. 2003. Autoinhibition of Bcr-Abl through its $\mathrm{SH} 3$ domain. Mol. Cell. 12:27-37.

70. Gross, A.W., Zhang, X., and Ren, R. 1999. Bcr-Abl with an $\mathrm{SH} 3$ deletion retains the ability To induce a myeloproliferative disease in mice, yet c-Abl activated by an $\mathrm{SH} 3$ deletion induces only lymphoid malignancy. Mol. Cell. Biol. 19:6918-6928.

71. Skorski, T., et al. 1998. The SH3 domain contributes to BCR/ABL-dependent leukemogenesis in vivo: role in adhesion, invasion, and homing. Blood. 91:406-418

72. McWhirter, J.R., and Wang, J.Y. 1993. An actin-binding function contributes to transformation by the Bcr-Abl oncoprotein of Philadelphia chromosomepositive human leukemias. EMBO J. 12:1533-1546.

73. Naldini, L., et al. 1986. Phosphotyrosine antibodies identify the p210c-abl tyrosine kinase and proteins phosphorylated on tyrosine in human chronic myelogenous leukemia cells. Mol. Cell. Biol. 6:1803-1811.

74. Freed, E., and Hunter, T. 1992. A 41-kilodalton protein is a potential substrate for the $\mathrm{p} 210 \mathrm{bcr}-\mathrm{abl}$ protein-tyrosine kinase in chronic myelogenous leukemia cells. Mol. Cell. Biol. 12:1312-1323.

75. Oda, T., et al. 1994. Crkl is the major tyrosinephosphorylated protein in neutrophils from patients with chronic myelogenous leukemia. J. Biol. Chem. 269:22925-22928.

76. Pendergast, A.M., et al. 1993. BCR-ABL-induced oncogenesis is mediated by direct interaction with the SH2 domain of the GRB-2 adaptor protein. Cell. 75:175-185.

77. Graziani, Y., Erikson, E., and Erikson, R.L. 1983. The effect of quercetin on the phosphorylation activity of the Rous sarcoma virus transforming gene product in vitro and in vivo. Eur. J. Biochem. 135:583-589.

78. Uehara, Y., Hori, M., Takeuchi, T., and Umezawa, H. 1986. Phenotypic change from transformed to normal induced by benzoquinonoid ansamycins accompanies inactivation of p60src in rat kidney cells infected with Rous sarcoma virus. Mol. Cell. Biol. 6:2198-2206.

79. Akiyama, T., et al. 1987. Genistein, a specific inhibitor of tyrosine-specific protein kinases. J. Biol. Chem 262:5592-5595.

80. Ogawara, H., Akiyama, T., Ishida, J., Watanabe, S., and Suzuki, K. 1986. A specific inhibitor for tyrosine protein kinase from Pseudomonas. J. Antibiot. 39:606-608.

81. Umezawa, H., et al. 1986. Studies on a new epidermal growth factor-receptor kinase inhibitor, erbstatin, produced by MH435-hF3. J. Antibiot. 39:170-173.

82. Yaish, P., Gazit, A., Gilon, C., and Levitzki, A. 1988. Blocking of EGF-dependent cell proliferation by EGF receptor kinase inhibitors. Science. 242:933-935

83. Hidaka, H., Inagaki, M., Kawamoto, S., and Sasaki, Y. 1984. Isoquinolinesulfonamides, novel and potent inhibitors of cyclic nucleotide dependent protein kinase and protein kinase C. Biochemistry. 23:5036-5041.

84. Anafi, M., Gazit, A., Gilon, C., Ben-Neriah, Y., and Levitzki, A. 1992. Selective interactions of transforming and normal abl proteins with ATP, tyrosine-copolymer substrates, and tyrphostins. J. Biol. Chem. 267:4518-4523.

85. Anafi, M., Gazit, A., Zehavi, A., Ben-Neriah, Y., and Levitzki, A. 1993. Tyrphostin-induced inhibition of p210bcr-abl tyrosine kinase activity induces K562 to differentiate. Blood. 82:3524-3529.

86. Osherov, N., and Levitzki, A. 1994. Epidermalgrowth-factor-dependent activation of the src-family kinases. Eur. J. Biochem. 225:1047-1053.

87. Kovalenko, M., et al. 1994. Selective platelet-derived growth factor receptor kinase blockers reverse sistransformation. Cancer Res. 54:6106-6114.

88. Bozulic, L., Morin, P., Jr., Hunter, T., and Hemmings, B.A. 2007. Meeting report: targeting the kinome -20 years of tyrosine kinase inhibitor research in Basel. Sci. STKE. 2007:pe8.

89. Zimmermann, J., et al. 1996. Phenylamino-pyrimidine (PAP) derivatives: a new class of potent and selective inhibitors of protein kinase C (PKC). Arch. Pharm. (Weinheim). 329:371-376.

90. Buchdunger, E., et al. 1995. Selective inhibition of the platelet-derived growth factor signal transduction pathway by a protein-tyrosine kinase inhibitor of the 2-phenylaminopyrimidine class. Proc. Natl. Acad. Sci. U. S. A. 92:2558-2562.

91. Buchdunger, E., et al. 1996. Inhibition of the Abl protein-tyrosine kinase in vitro and in vivo by a 2-phenylaminopyrimidine derivative. Cancer Res. 56:100-104.

92. Druker, B.J., et al. 1996. Effects of a selective inhibitor of the $\mathrm{Abl}$ tyrosine kinase on the growth of $\mathrm{Bcr}$ Abl positive cells. Nat. Med. 2:561-566.

93. Carroll, M., et al. 1997. CGP 57148, a tyrosine kinase inhibitor, inhibits the growth of cells expressing BCR-ABL, TEL-ABL, and TEL-PDGFR fusion proteins. Blood. 90:4947-4952.

94. Druker, B.J., et al. 2001. Efficacy and safety of a specific inhibitor of the BCR-ABL tyrosine kinase in chronic myeloid leukemia. N. Engl. J. Med. 344:1031-1037.

95. Druker, B.J., et al. 2001. Activity of a specific inhibitor of the BCR-ABL tyrosine kinase in the blast crisis of chronic myeloid leukemia and acute lymphoblastic leukemia with the Philadelphia chromosome. N. Engl.J. Med. 344:1038-1042.

96. Sawyers, C.L., et al. 2002. Imatinib induces hematologic and cytogenetic responses in patients with chronic myelogenous leukemia in myeloid blast crisis: results of a phase II study. Blood. 99:3530-3539.

97. Buchdunger, E., et al. 2000. Abl protein-tyrosine kinase inhibitor STI571 inhibits in vitro signal transduction mediated by c-kit and platelet-derived growth factor receptors. J. Pharmacol. Exp. Ther. 295:139-145.

98. Heinrich, M.C., et al. 2003. PDGFRA activating mutations in gastrointestinal stromal tumors. Science. 299:708-710.

99. Demetri, G.D., et al. 2002. Efficacy and safety of imatinib mesylate in advanced gastrointestinal stromal tumors. N. Engl. J. Med. 347:472-480.

100.Gorre, M.E., et al. 2001. Clinical resistance to STI571 cancer therapy caused by BCR-ABL gene mutation or amplification. Science. 293:876-880

101.Shah, N.P., et al. 2002. Multiple BCR-ABL kinase domain mutations confer polyclonal resistance to the tyrosine kinase inhibitor imatinib (STI571) in chronic phase and blast crisis chronic myeloid leukemia. Cancer Cell. 2:117-125.

102.Shah, N.P., et al. 2004. Overriding imatinib resistance with a novel ABL kinase inhibitor. Science. 305:399-401.

103.Azam, M., Latek, R.R., and Daley, G.Q. 2003. Mechanisms of autoinhibition and STI-571/imatinib resistance revealed by mutagenesis of BCR-ABL. Cell. 112:831-843.

104.Schindler, T., et al. 2000. Structural mechanism for STI-571 inhibition of Abelson tyrosine kinase. Science. 289:1938-1942.

105.Weisberg, E., et al. 2005. Characterization of AMN107, a selective inhibitor of native and mutant Bcr-Abl. Cancer Cell. 7:129-141.

106. Cowan-Jacob, S.W., et al. 2007. Structural biology contributions to the discovery of drugs to treat chronic myelogenous leukaemia. Acta Crystallogr. D Biol. Crystallogr. 63:80-93.

107. Young, M.A., et al. 2006. Structure of the kinase domain of an imatinib-resistant $\mathrm{Abl}$ mutant in complex with the Aurora kinase inhibitor VX-680. Cancer Res. 66:1007-1014.

108.Carter, T.A., et al. 2005. Inhibition of drug-resistant mutants of ABL, KIT, and EGF receptor kinases. Proc. Natl. Acad. Sci. U. S. A. 102:11011-11016.

109.Jamieson, C.H., et al. 2004. Granulocyte-macrophage progenitors as candidate leukemic stem cells in blast-crisis CML. N. Engl. J. Med. 351:657-667.

110.Salomon, A.R., et al. 2003. Profiling of tyrosine phosphorylation pathways in human cells using mass spectrometry. Proc. Natl. Acad. Sci. U. S. A. 100:443-448.

111.Goss, V.L., et al. 2006. A common phosphotyrosine signature for the $\mathrm{Bcr}-\mathrm{Abl}$ kinase. Blood. 107:4888-4897.

112.Wong, S., et al. 2004. Sole BCR-ABL inhibition is insufficient to eliminate all myeloproliferative disorder cell populations. Proc. Natl. Acad. Sci. U. S. A. 101:17456-17461.

113. Hantschel, O., and Superti-Furga, G. 2005. Regulation of the $\mathrm{c}-\mathrm{Abl}$ and $\mathrm{Bcr}-\mathrm{Abl}$ tyrosine kinases. Nat. Rev. Mol. Cell Biol. 5:33-44. 